\title{
SISTEM INFORMASI TATA KELOLA PERPUSTAKAAN BERBASIS WEB PADA DINAS KEARSIPAN DAN PERPUSTAKAAN PROVINSI GORONTALO
}

\author{
${ }^{1}$ M. Salim, ${ }^{2}$ Sulistiawati R.N.Ahmad, ${ }^{3}$ Danial Saleh \\ 1,2,3 Stmik Ichsan Gorontalo, Indonesia

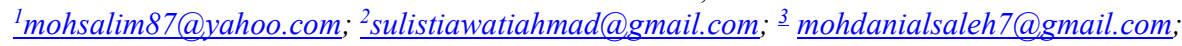

\begin{tabular}{l}
\hline \hline Article Info \\
\hline Article history: \\
Received, 24/08/2021 \\
Revised, 07/09/2021 \\
Accepted, 13/11/2021 \\
\hline Kata Kunci: \\
Tata Kelola \\
Kearsipan \\
perpustakaan \\
Website \\
Sistem Informasi \\
\hline \hline
\end{tabular}

Keywords:

Governance

Archives

library

Website

Information Systems

\begin{abstract}
ABSTRAK
Ditengah kondisi Pandemi, pemerintah menerapkan sistem kerja dari rumah (WFH). Namun tidak semua bisa dikerjakan dari rumah, beberapa pegawai tetap masuk kantor dengan menerapkan protocol Kesehatan ketat. Pandemi Covid-19 menjadi tantangan bagi ASN, tantangan tersebut adalah tetap produktif selama pandemi. Tidak hanya bertanggung jawab kepada diri sendiri, ASN dituntur berperan dalam menjadi contoh masyarakat dalam memutus rantai penyebaran Covid-19 di Indonesia. Penelitian bertujuan untuk mempermudah proses pengolahan data pustaka dalam bentuk penyimpanan database, menghasilkan laporan yang akurat, Sebelumnya telah ada system yang berjalan di Dinas Kearsipan dan perpustakaan provinsi Gorontalo, kelemahan sistem sebelumnya adalah bersifat intranet, sehingga pegawai harus ke kantor untuk menginput data. Dengan adanya Sistem informasi tata kelola perpustakaan berbasis web pegawai dapat mengerjakan tugasnya dikantor dan dirumah tanpa harus menginput dua kali sekaligus meminimalisir kesalahan yang terjadi karena pegawai di Dinas arsip dan kepustakaan secara bergantian masuk ke kantor dan bekerja dirumah sesuai dengan jadwal masing - masing. Aplikasi Sistem Informasi Tata Kelola Perpustakaan Berbasis Web Pada Dinas Kearsipan dan Perpustakaan Provinsi Gorontalo dapat memberikan kemudahan dalam pengolahan Data Pustaka dan membantu pegawai dalam mengerjakan tugasnya dari rumah (WFH).
\end{abstract}

\section{ABSTRACT}

During pandemic conditions, the government implemented a work from the home system (WFH). But not all can be done from home, some employees still enter the office by applying strict health protocols. The Covid-19 pandemic is a challenge for ASN, the challenge is to remain productive during the pandemic. Not only responsible to yourself but ASN is also led to playing a role in serving as an example of a society in breaking the chain of the spread of Covid-19 in Indonesia. The research aims to facilitate the process of processing library data in the form of database storage, produce accurate reports, Previously there has been a system running in the Archival Office and Gorontalo provincial library, the weakness of the previous system is an intranet, so employees must go to the office to input data. With the web-based library, governance information system employees can do their duties in the office and at home without having to input twice while minimizing the errors that occur because employees in the archives and library departments alternately enter the office and work at home according to their respective schedules. Web-Based Library Governance Information System Application at the Ministry of Archives and Library of Gorontalo Province can provide convenience in processing Data Library and assist employees in doing their duties from home (WFH).

Penulis Korespondensi:

M.Salim,

Program Studi Sistem informasi,

STMIK ICHSAN GORONTALO, 
Email: mohsalim87@yahoo.com

\section{PENDAHULUAN}

Republik Rakyat Tiongkok dilanda wabah coronavirus disease that was discovered in 2019 (COVID-19) yang menyebar keseluruh penjuru dunia termasuk Indonesia dan segera ditetapkan World Health Organization (WHO) sebagai pandemi. Berdasarkan ketetapan WHO, Pemerintah Indonesia juga telah menetapkan COVID 19 sebagai bencana nasional non alam berupa wabah penyakit yang wajib dilakukan penanggulangan dalam peningkata kasus. [1] Menteri Pendayagunaan Aparatur Negara dan Reformasi Birokrasi (Menpan dan RB) menerbitkan Surat Edaran Nomor 19 Tahun 2020 tentang Pedoman Pelaksanaan Tugas Kedinasan Dengan Bekerja Di Rumah/Tempat Tinggalnya (Work From Home/WFH) Bagi Aparatur Sipil Negara (ASN) Sebagai Upaya Pencegahan Dan Meminimalisir Penyebaran COVID-19. Kebijakan WFH merupakan sesuatu yang baru bagi aparatur pemerintah di Indonesia. Undang-Undang Nomor 5 Tahun 2014 tentang Aparatur Sipil Negara (UUASN) dan Peraturan Pemerintah Nomor 11 Tahun 2017 tentang Manajemen Pegawai Negeri Sipil (PP Manajemen PNS) belum mengatur tentang kebijakan tersebut. [1]

Ditengah kondisi Pandemi, pemerintah menerapkan sistem kerja dari rumah (WFH). Namun tidak semua bisa dikerjakan dari rumah, beberapa pegawai tetap masuk kantor dengan menerapkan protocol Kesehatan ketat. Pandemi Covid-19 menjadi tantangan bagi ASN, tantangan tersebut adalah tetap produktif selama pandemi. Tidak hanya bertanggung jawab kepada diri sendiri, ASN dituntur berperan dalam menjadi contoh masyarakat dalam memutus rantai penyebaran Covid-19 di Indonesia.[2] Tantangan lainnya, yaitu perubahan sistem kerja yang disesuaikan dengan kebijakan lainnya. Most empirical work on the effects of working from home on commuting tends to corroborate the intuitive notion that being able to avoid the commute one day in the week makes workers more willing to accept a longer commute on the other days of the week (Jiang 2008;Zhu 2012; Kim et al. 2015). [3] Contohnya sistem kerja ASN yang diubah menjadi Work From Home (WFH) tidak boleh disalahartikan. Pemanfaatan teknologi juga menjadi salah satu alternatif ASN memberikan layanan di tengah pandemi, sehingga meminimalisir pertemuan tatap muka antar pemohon dan penyedia layanan. literasi dan kultur digital perlu ditingkatkan dalam pengembangan kompetensi ASN. Mengingat saat ini telah memasuki era serba digital, serba otomatis, tidak selalu di kantor untuk bekerja, dan tidak selalu di pusdiklat untuk belajar. [1].

Penggunaan sistem komputerisasi menjadi suatu keharusan yang biasanya diterapkan diberbagai bidang kehidupan manusia seperti bisnis, pendidikan serta di bidang sosial kemasyarakatan. Meningkatnya kebutuhan informasi pada berbagai skala kehidupan diiringi pula dengan perkembangan ilmu pengetahuan dan teknologi. Dengan berkembangnya ilmu pengetahuan dan teknologi terutama di bidang teknologi informasi, berbagai cara ditempuh oleh suatu instansi atau lembaga untuk memperoleh informasi yang dibutuhkan untuk mempercepat proses informasi. Dengan adanya informasi maka aktifitas instansi atau lembaga dapat berjalan lancar. [5][6]

Hasil observasi yang dilakukan pada Staf dibidang pelayanan dan teknologi, bagian kepegawaian dan tatalaksana mengalami kesulitan untuk memproses data pustaka walaupun telah menggunakan komputer sebagai sarana penunjangnya, pengolahan data pustaka disimpan menggunakan Ms.office. Hal itu mempengaruhi kinerja pegawai, Tuntutan pekerjaan terhambat dengan tidak adanya aplikasi yang menunjang pegawai bekerja dari rumah dan sinkronisasi antara pegawai yang tengah bekerja dirumah dengan pegawai yang bergantian masuk kerja sehingga pekerjaan menjadi dua kali dan tidak efisien. Sebelumnya telah ada system yang berjalan di Dinas Kearsipan dan perpustakaan provinsi Gorontalo, kelemahan system sebelumnya adalah bersifat intranet, sehingga pegawai harus ke kantor untuk menginput data. Dengan adanya Sistem informasi tata kelola perpustakaan berbasis web pegawai dapat mengerjakan tugasnya dikantor dan dirumah tanpa harus menginput dua kali sekaligus meminimalisir kesalahan yang terjadi karena pegawai di Dinas arsip dan kepustakaan secara bergantian masuk ke kantor dan bekerja dirumah sesuai dengan jadwal masing masing.

\section{METODE PENELITIAN}

Metode penelitian deskriptif adalah metode yang dilakukan untuk mengetahui gambaran, keadaan, suatu hal dengan cara mendeskripsikannya sedetail mungkin berdasarkan fakta yang ada.[7]

Tahapan penelitian: [8][9]

1. Identifikasi Masalah 
Langkah awal yang dilakukan adalah melakukan identifikasi masalah, Penulis melakukan obervasi awal ke Dinas kearsipan dan perpustakaan provinsi Gorontalo dan memisahkan variable yang menunjang penelitian.

2. Jenis Dan Sumber Data

a. Data primer, Data didapatkan melalui wawancara dengan narasumber dan observasi Dinas kearsipan dan perpustakaan provinsi Gorontalo selama beberapa waktu.

b. Data Sekunder, Untuk melengkapi data dalam penelitian maka penulis mengambil dari beberapa literatur, buku, jurnal dan informasi lainnya yang ada hubungannya dengan masalah yang sedang diteliti. [10]

3. Metode Pengumpulan Data [11]

a. Langkah awal adalah melakukan interview dan analisa data Pengumpulan data melalui analisa langsung dengan calon pengguna aplikasi (Petugas kearsipan) yang nantinya akan melakukan impelementasi aplikasi.

b. Survey

Agar data lebih valid maka dilakukan pengumpulan data melalui survey penggunaan aplikasi yang saat ini sudah terbangun dalam dinas kearsipan dan perpustakaan.

c. Studi Pustaka

Langkah selanjutnya adalah melakukan studi kepustakaan untuk mencari referensi penelitian.

4. Tahap Analisis

Setelah pengumpulan data dan observasi dilakukan maka langkah selanjutnya adalah tahap analisis.

\section{HASIL DAN ANALISIS}

Analisa Sistem adalah suatu proses yang memilah masalah kedalam elemen yang lebih kecil untuk dipelajari, dengan tujuan memecah suatu persoalan dari suatu sistem yang berjalan. [13] Hasil akhir dari proses ini adalah solusi dalam bentuk spesifikasi sistem yang baru, Dalam pendekatan analisis masalah, seluruh pengaruh kendala utama didefinisikan dan dievaluasi dalam bentuk pengaruh yang lebih kuat pada seluruh titik keputusan dalam sistem, sistem yang berjalan pada Dinas Perpustakaan Dan Arsip Daerah Provinsi Gorontalo sudah menggunakan sistem komputer tetapi masih perlu penyempurnaan. Oleh karena itu dalam pengolahannya masih banyak kekurangan yang perlu diperhatikan khususnya pada masalah efisiensi, efektifitas, ketepatan dan keamanan pada sistem yang dirancang. [8]

Penggunaan Aplikasi sistem informasi ini dapat meminimalisir redudansi data dan membuat pegawai lebih efektif dan efisien sehingga tidak perlu menginput dua kali dalam satu system. Pelaporan lebih mudah dan bisa dicetak kapanpun dibutuhkan oleh pimpinan.

Berikut adalah diagram konteks dari aplikasi system informasi Tata Kelola perpusatakaan.

\section{Diagram Konteks}




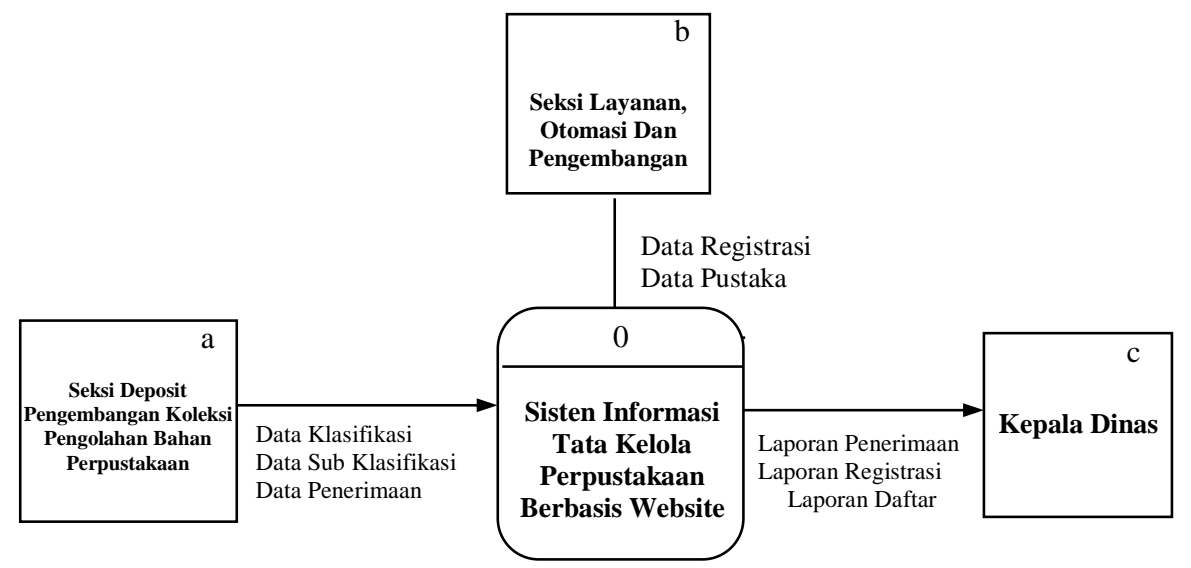

Gambar 1. Diagram Konteks

\section{Tampilan Program}

a. Menu Login Admin

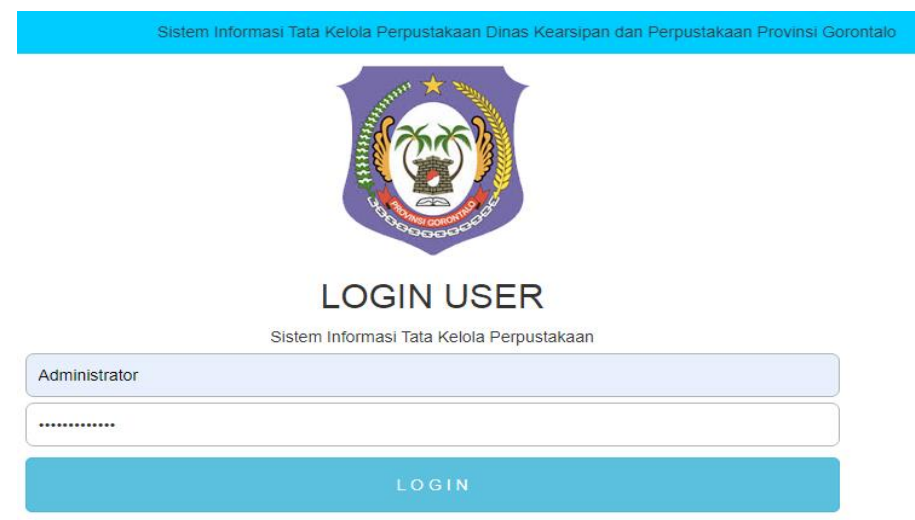

Gambar 2. Menu login

Menu Login untuk admin yang mau masuk pada aplikasi, dengan mengisi username dan password seperti gambar diatas.

b. Menu Utama

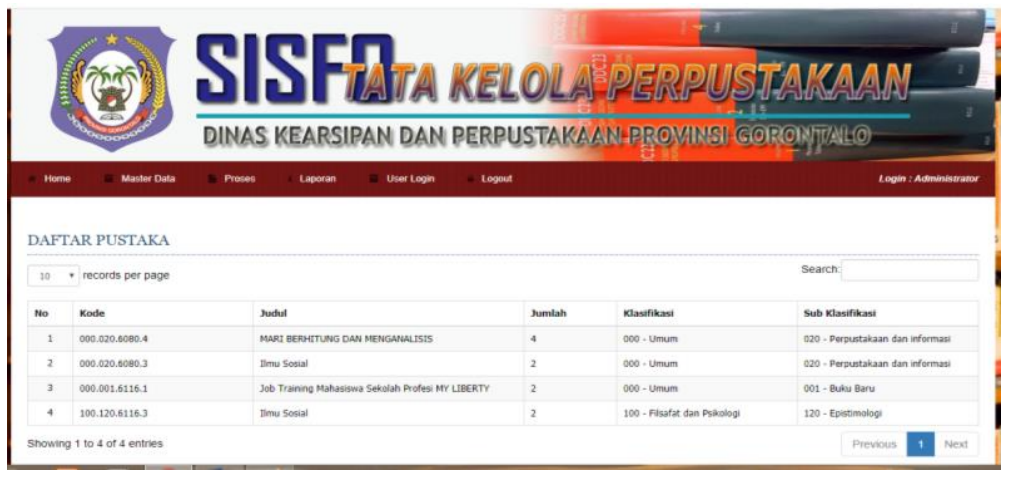

Gambar 3. Menu Utama

Pada Gambar 3 diatas merupakan gambar Menu utama yang dikelola oleh Admin. Pada tampilan yang disediakan merupakan menu Home (Beranda), Master Data, Proses, laporan dan user login.

c. Form Tambah Data Klasifikasi 


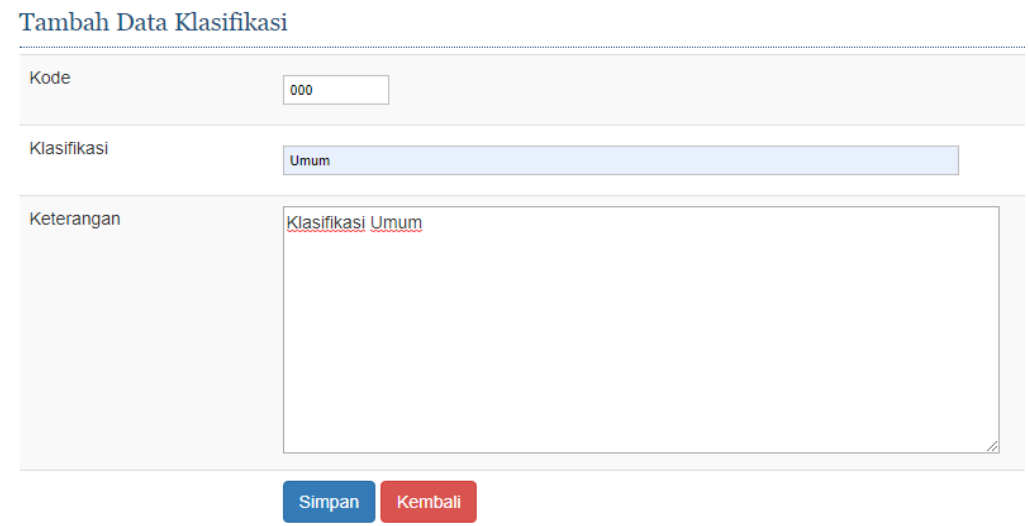

Gambar 4. Tambah Data Klasifikasi

Form Tambah Data Klasifikasi berfungsi untuk menginput kd_klasifikasi, nama_klasifikasi, ket_klasifikasi, pilihan Simpan untuk menyimpan Tambah Data Klasifikasi dan Kembali untuk kembali pada menu inputan

d. Form Tambah Data Sub Klasifikasi

Tambah Data Sub Klasifikasi

\begin{tabular}{l|l|}
\hline Kode & \multicolumn{1}{|l|}{001} \\
\hline Sub Klasifikasi & Buku Baru \\
\hline Klasifikasi & Simpan \\
\hline & Kembali \\
\hline
\end{tabular}

Gambar 5. Tambah Data sub Klasifikasi

Form Tambah Data Sub Klasifikasi berfungsi untuk menginputkode sub klasifikasi, nama sub klasifikasi, kodeklasifikasi, pilihan Simpan untuk menyimpan Tambah Data Sub Klasifikasi dan Kembali untuk kembali pada menu inputan.

e. Tambah Data Penerimaan

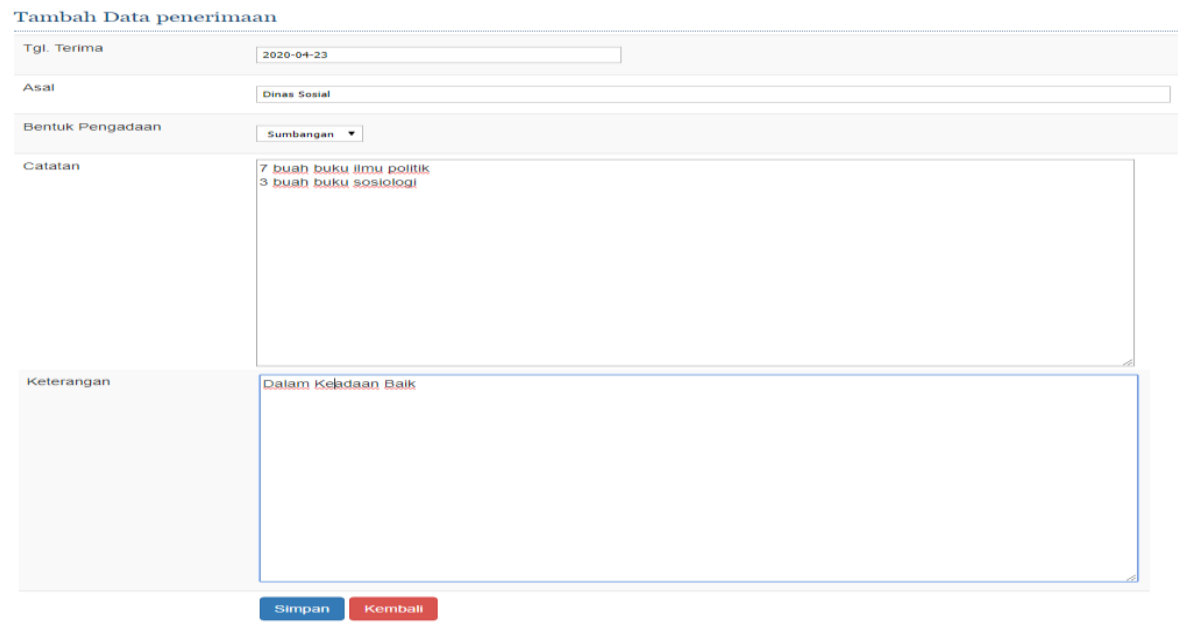

Gambar 6. Tambah Data Penerimaan

Form Tambah Data Penerimaan berfungsi untuk menginput id_terima, tgl_terima, Asal, pengadaan, catatan, keterangan, pilihan Simpan untuk menyimpan Tambah Data Penerimaan dan Kembali untuk kembali pada menu inputan.

f. Tambah Data Registrasi 


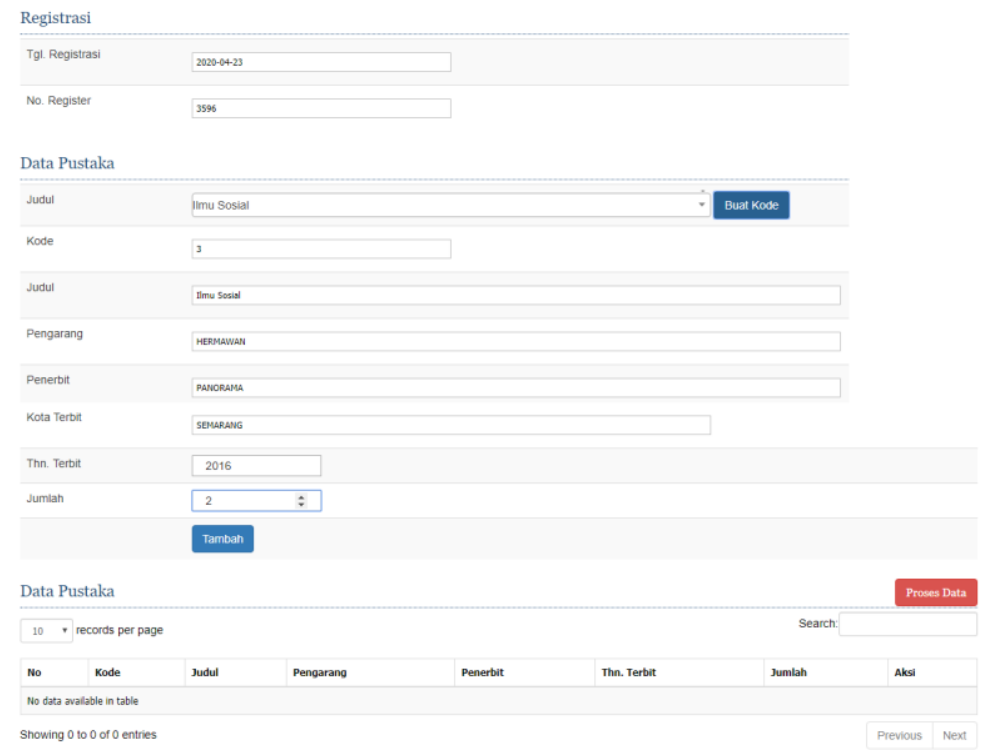

Gambar 7. Tambah Data Registrasi

Form Tambah Data Registrasiberfungsi untuk menginput tgl_regis, no_regis, judul, pengarang, penerbit, kota terbit, thn_terbit, jumlah, pilihan Simpan untuk menyimpan Tambah Data Registrasi dan Kembali untuk kembali pada menu inputan.

g. Tambah Data Pustaka

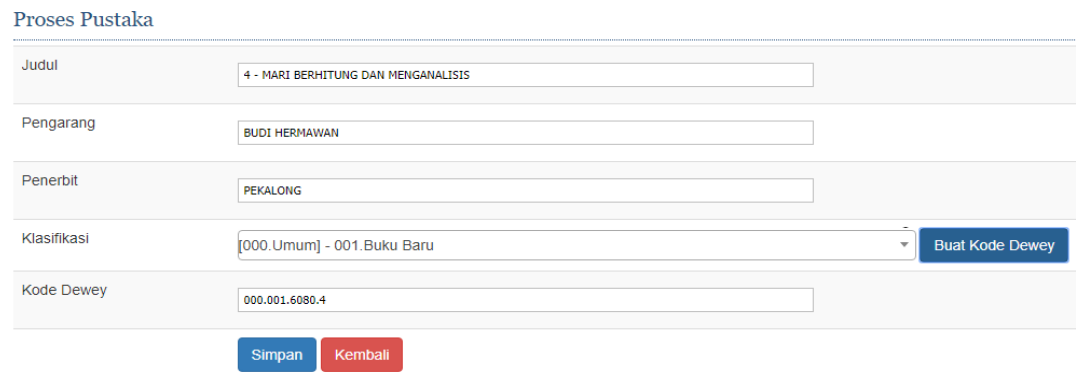

Gambar 8. Tambah Data Pustaka

Form Tambah Data Pustaka berfungsi untuk menginput judul, pengarang, penerbit, klasifikasi, kodedewey, pilihan Simpan untuk menyimpan Tambah Data Pustaka dan Kembali untuk kembali pada menu inputan.

\section{Pembahasan hasil analisis}

Penelitian memakai system yang berjalan sebelumnya di Dinas Kearsipan dan perpustakaan provinsi Gorontalo menjadi tolok ukur dari pembuatan system baru. Dengan memperhitungkan sifat familiar dan factor sisi user yang harus belajar secara mandiri system yang baru guna meminimalisir kesalahan dalam input.

Maka oleh penulis dibuatlah sebuah aplikasi system informasi Tata kelola kearsipan buat pegawai dinas kearsipan dan perpustakaan. Kelemahan system yang lama adalah semuanya diinput dengan jaringan intranet. Sedangkan Sistem informasi tata kelola perputakaan dibuat online agar pegawai yang sedang bekerja dirumah dapat melakukan pekerjaannya dirumah dan dikantor.

Form - form input yang dibuat semudah mungkin agar lebih mudah dan familiar digunakan. Pegawai tidak akan mengalami kesulitan dalam mengaksesnya. Setelah mendapatkan username dan password dari admin maka User dalam hal ini pegawai Dinas tata kelola perpustakaan dapat mengakses system informasi tata kelola perpustakaan melalui browser Mozilla, Internet Explorer dan Chrome.

\section{KESIMPULAN}


Penelitian yang dilakukan di Dinas Kearsipan dan perpustakaan Provinsi Gorontalo menemukan beberapa masalah yang terjadi pada kearsipan dalam kantor tersebut. Sebelum masa Pademi, pekerjaan dapat diselesaikan dengan system yang telah ada sebelumnya dikantor itu berupa penginputan data setiap harinya. Sejak diturunkannya kebijakan bekerja dari rumah, seluruh kantor menerapkan protocol kesehatan, Aparatur sipil Negara (ASN) harus menyesuaikan diri dengan situasi pandemi. Sistem informasi tata kelola perpustakaan membantu ASN untuk tetap produktif dan bekerja dari rumah secara online. Para pegawai lebih mudah saling berkoordinasi baik yang sedang berada dirumah dan dikantor dengan tidak lagi menginput dua kali pada system.

\section{UCAPAN TERIMA KASIH}

Ucapan terima kasih tidak terhingga pada semua unsur yang membantu terlaksananya penelitian, dimasa pandemi dan ditengah pembatasan sosial yang diterapkan, banyak bantuan yang didapatkan penulis untuk mendapatkan data penelitian.

\section{REFERENSI}

[1] R. A. Syaefudin, W. H. Suseno, and G. Teravosa, "KEBIJAKAN BEKERJA DARI RUMAH ( WORK FROM HOME ) BAGI APARATUR SIPIL NEGARA PADA KEMENTERIAN KESEHATAN," E-Journal BKN Civ. Serv., vol. 14, no. 1 juni, pp. 85-92, 2020, [Online]. Available: https://jurnal.bkn.go.id/index.php/asn/article/view/237.

[2] D. Mustajab, A. Bauw, A. Rasyid, A. Irawan, M. A. Akbar, and M. A. Hamid, "Working from Home Phenomenon as an Effort to Prevent COVID-19 Attacks and Its Impacts on Work Productivity," Int. J. Appl. bussines TIJAB, vol. 4, no. 1, pp. 13-21, 2020.

[3] D. De Vos and M. Van Ham, "Working from home and the willingness to accept a longer," Ann. Reg. Sci., vol. 61, no. 2, pp. 375-398, 2018, doi: 10.1007/s00168-018-0873-6.

[4] N. Krasulja, M. Vasiljevic-Blagojevic, and I. Radojevic, "Working from home as alternative for acheving work-life balance," Ekonomika, vol. 61, no. 2, pp. 131-142, 2015, doi: 10.5937/ekonomika1502131k.

[5] M. Salim and A. Sulistiawati, "Sistem Pendukung Keputusan Seleksi Bantuan Operasional Madrasah Menggunakan Metode Weighted Aggregatedsum Product Assessment Berbasis Android Pada Kementerian Agama Kabupaten Pohuwato," JSAI (Journal Sci. Appl. Informatics), vol. 3, no. 1, pp. 25-30, 2020, doi: 10.36085/jsai.v3i1.608.

[6] P. S. Kumar, P. M. S., \& Aithal, "Working From Home -a Transition in the Concept of Workplace," Int. J. Curr. Res. Mod. Educ., vol. 1, no. 1, pp. 244-249, 2016, doi: https://doi.org/10.5281/zenodo.161110.

[7] Riduwan, Skala Pengukuran Variabel-Variabel Penelitian. Bandung: Alfabeta, 2008.

[8] Sugiyono, Metode Penelitian Kombinasi (Mixed Methods). Bandung: Alfabeta, 2014.

[9] Sugiono, Metode penelitian kuantitatif, kualitatif dan research and development. Bandung: Alfabeta, 2017.

[10] H. M. Rumere, A. R. Tanaamah, and M. N. N. Sitokdana, "Analisis Kinerja Tata Kelola Teknologi Informasi Pada Dinas Perpustakaan Dan Kearsipan Daerah Kota Salatiga Menggunakan Framework Cobit 5.0," Sebatik, vol. 24, no. 1, pp. 14-21, 2020, doi: 10.46984/sebatik.v24i1.926.

[11] M. Salim, "Sistem Pendukung Keputusan Penerimaan Calon Guru Honor di SMK Gotong Royong Gorontalo Menggunakan Metode TOPSIS," J. Inform. UPGRIS, vol. 4, no. 1, pp. 28-33, 2018.

[12] D. A. Nugraha, "PENGELOLAAN KEARSIPAN BERBASIS ELEKTRONIK DI DINAS PERPUSTAKAAN DAN KEARSIPAN KABUPATEN CIAMIS," Din. J. ilmu Adm. negara, vol. 6, no. 4, pp. 203-213, 2019.

[13] muhammad. D. Tadjudin, sistem informasi. Daerah istimewa Yogyakarta: The Deepublish, 2020. 